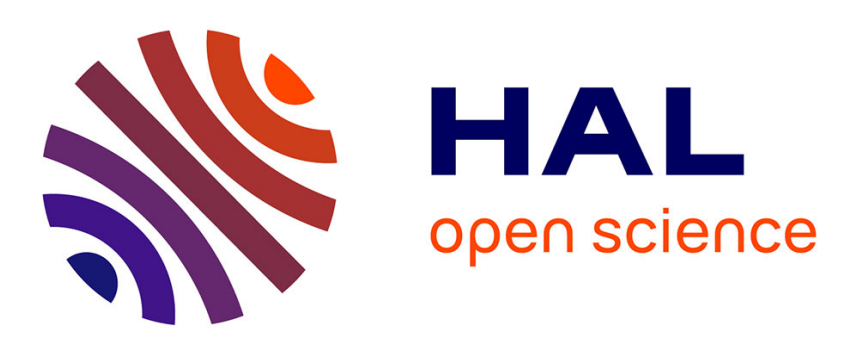

\title{
Influence of parent's eating attitudes on eating disorders in school adolescents
}

J. Canals, C. Sancho, M. V. Arija

\section{To cite this version:}

J. Canals, C. Sancho, M. V. Arija. Influence of parent's eating attitudes on eating disorders in school adolescents. European Child and Adolescent Psychiatry, 2009, 18 (6), pp.353-359. 10.1007/s00787009-0737-9 . hal-00478096

\section{HAL Id: hal-00478096 https://hal.science/hal-00478096}

Submitted on 30 Apr 2010

HAL is a multi-disciplinary open access archive for the deposit and dissemination of scientific research documents, whether they are published or not. The documents may come from teaching and research institutions in France or abroad, or from public or private research centers.
L'archive ouverte pluridisciplinaire HAL, est destinée au dépôt et à la diffusion de documents scientifiques de niveau recherche, publiés ou non, émanant des établissements d'enseignement et de recherche français ou étrangers, des laboratoires publics ou privés. 
J. Canals

C. Sancho

M.V. Arija

\section{Influence of parent's eating attitudes on eating disorders in school adolescents}

Received: 5 May 2008

Accepted: 15 September 2008

Published online: 16 February 2009
J. Canals, MD ( $\square)$

Department of Psychology

Rovira i Virgili University

Ctra. Valls s/n

43007 Tarragona, Spain

E-Mail: josefa.canals@urv.cat

C. Sancho - M.V. Arija, MD

Preventive Medicine and Public

Health Unit

Rovira i Virgili University

Tarragona, Spain
Abstract Objective To investigate the relationship between parents' cognitive and behavioural dimensions and the risk of eating disorders (ED) in non-clinical adolescents. Methods From an initial sample of 1,336 boys and girls with a mean age of 11.37 , a total of 258 subjects were selected either as being at risk of ED or as controls. These subjects and their parents comprised the sample at $\mathrm{T} 1$ and were followed-up 2 years later (T2). We examined disordered eating attitudes, body dissatisfaction (BD), body mass index (BMI) and ED diagnoses in the adolescents at two points in time. We also used the Eating Disorder Inventory- 2 to examine the disordered eating attitudes of their parents at T1. Results The mother's BD, drive for thinness
(DT), ineffectiveness and interoceptive awareness, and the father's DT and perfectionism were related to long-term ED. Logistic regression showed that predictors of ED were being female, mother's DT and social insecurity, and adolescent's BD. The BMI was not a predictor in this model. Father's perfectionism was a risk factor of ED. Conclusion Specific cognitive and behavioural dimensions of ED in both parents can influence the development of an ED in early adolescents. This should be taken into account in the prevention and family oriented treatment of ED.

Key words eating disorders adolescents - children longitudinal study parents

\section{Introduction}

The family plays an important role in the risk of children developing eating disorders (ED). Several studies have focussed on the relationship between patients with anorexia and bulimia nervosa and the adolescent perception of family functioning [6]; the mother's perception of family functioning [3]; the family environment [27]; and parenting style [31]. These relationships have possible implications for the course of treatment but they do not determine whether family processes cause an ED or whether these processes are caused by the presence of a sick family member. Other studies on predicting the onset of ED have investigated family factors perceived by adolescents in non-clinical samples. Some authors have reported that family functioning was a predictor of eating symptoms [26] or ED in a community sample [2], while others [33] have reported that it was not a significant predictor. Benninghoven et al. [3] showed that an alternative viewpoint is that the family can transmit issues that are more directly related to eating pathology such as weight, shape, and eating behaviour. Perceived weight-related pressure [34] and the importance of physical appearance for the family 
$[7,15]$ seem to influence the development of disordered eating patterns. Parental social values that emphasize physical attractiveness, admire thinness and encourage behaviours such as dieting and exercise in the pursuit of an ideal body shape may contribute to eating problems in their children [7]. Within the family, the mother is a primary role model and seems to be a powerful influence on daughters. Some authors found that the mothers of girls with disordered eating patterns were more critical of their daughters' appearance than the mothers of healthy girls [13], and that children's attempts to lose weight were related to parental comments about their weight and to children's own complaints about their own weight [25]. Mothers of children with ED had higher bulimic factor scores in the Eating Attitudes Test-26, more binge-eating episodes, and more ED symptoms than those in a control group [9]. Likewise, evidence suggests that the children of mothers with ED are at a greater risk of feeding or eating problems and other disorders in several domains [18].

Some studies suggest that the effect of family factors is different for boys than for girls. In a sample of high school students, Pritchard [20] reported that maternal and paternal eating habits were significantly related to self-reported body satisfaction for girls but that only paternal eating habits were related to body satisfaction for boys.

The mothers and fathers of subjects with ED have been described as having various personality and eating attitudes. Elevated perfectionism has been found in the mothers of individuals with anorexia nervosa [32], and predicted maladaptive eating in non-clinical late adolescents offspring [17].

In this study we examine the relationships between specific cognitive and behavioural dimensions of ED in both parents and the risk of ED in non-clinical adolescents. Our study has a longitudinal design, so we hypothesize that parents influence eating problems from early adolescence, and that the mother and the father do not have the same influence.

\section{Methods}

\section{Subjects}

The initial sample of this longitudinal study consisted of 1,336 schoolchildren with an age range of 9.413.5 years $($ mean $=11.37, \mathrm{SD}=0.62$ ). Of these children, 649 were boys $(M=11.35$ years, $\mathrm{SD}=0.64)$ and 687 were girls $(M=11.39$ years, $S D=0.61)$. The participants were recruited from 17 primary schools randomly selected from the local area (the city and suburbs of Tarragona, Catalonia, Spain) to obtain a representative sample of children in terms of social and cultural background. Tarragona is a Mediterranean city with around 113,000 inhabitants of above-average socioeconomic status. The study was divided into two stages. First we assessed the initial sample with a twophase design. In the first of these phases, a screening test of ED children eating attitudes test (ChEAT) was administered to all the subjects in the initial sample to select those that were at risk. Of the 173 participants whose score was above or equal to the cutoff score, 141 (69 boys and 72 girls) participated as the risk group. These participants and a control group of 117 (59 boys and 58 girls) formed the sample for the second phase. The participants of this control group were randomly selected from those children with a score below the cutoff and with similar ages, genders and types of school. This second phase of the study was denoted as Time 1 (T1) ( $n=258 ; 128$ boys and 130 girls). In T1 a total of 174 mothers and 66 fathers answered the eating disorder inventory (EDI-2): 52 parents, 122 single mothers and 14 single fathers fulfilled the EDI-2. The sociodemographical characteristics of the families are shown in Table 1.

Two years later, the T1 sample was followed up. At this second time (T2), 200 students (93 boys and 107 girls) participated: 113 were subjects at risk and 87 were controls with an age range of 13-15 years (boys $M=13.78, \mathrm{SD}=0.750$ and girls $M=13.79$, $\mathrm{SD}=0.712$ ).

The estimated prevalence of any ED in T1 was $3.44 \%$ ( 21 boys and 25 girls). In T2, 11 boys and 40 girls were diagnosed with some form of ED (3.81\%). Table 2 shows the number of participants with each type of ED. Detailed information concerning eating pathologies is referred in Sancho et al. [24].

Table 1 Sociodemographical characteristics of the families in the sample

\begin{tabular}{|c|c|c|}
\hline & $\begin{array}{l}\text { Risk (\%) } \\
(n=141)\end{array}$ & $\begin{array}{l}\text { No risk }(\%) \\
(n=117)\end{array}$ \\
\hline Living in a nuclear family & 81.1 & $90.4^{*}$ \\
\hline Living only with mother & 12.6 & 8.7 \\
\hline Living only with father & 3.5 & 0.9 \\
\hline Living only with grandparents & 2.8 & $0.0^{*}$ \\
\hline Living with siblings & 89.6 & 82.5 \\
\hline Separated or divorced parents & 17.5 & $9.6^{*}$ \\
\hline Living with father or mother's partner & 7.0 & 3.5 \\
\hline $\begin{array}{l}\text { Living with the offspring of their } \\
\text { father or mother's partner }\end{array}$ & 5.6 & 1.7 \\
\hline \multicolumn{3}{|l|}{ Socioeconomic status father: } \\
\hline Low & 22.6 & 20.2 \\
\hline Medium & 59.1 & 58.7 \\
\hline High & 18.2 & 21.1 \\
\hline \multicolumn{3}{|l|}{ Socioeconomic status mother: } \\
\hline Low & 37.9 & 37.5 \\
\hline Medium & 47.9 & 50.9 \\
\hline High & 14.3 & 11.6 \\
\hline
\end{tabular}

${ }^{*} P<0.05$ 
Table 2 Number of participants with eating disorder diagnoses at $\mathrm{T} 1$ and $\mathrm{T} 2$

\begin{tabular}{lcllllll}
\hline & EDNOS1 & EDNOS3 & EDNOS4 & BED & $\begin{array}{l}\text { Subclinical } \\
\text { anorexia }\end{array}$ & $\begin{array}{l}\text { Subclinical } \\
\text { bulimia }\end{array}$ & Bulimia \\
\hline T1 & 29 & 1 & 1 & 1 & 14 & - & - \\
T2 & 5 & 6 & - & 3 & 32 & 2 & 3 \\
\hline
\end{tabular}

EDNOS1, 3, 4 Eating Disorders Not Otherwise Specified type 1, type 3, type 4; $B E D$ binge eating disorder or EDNOS type 6

\section{Measures}

\section{Children Eating Attitudes Test}

The ChEAT [16] is a well-established 26-item scale designed to assess maladaptive or problematic eating attitudes and behaviours among children. An experimental adapted Spanish version of the ChEAT was used for this study [23]. The difference between this version and the original scale is that six of the original 26 items were deleted because they were not deemed appropriate for this age group by the Education Department of the Autonomous Catalan Government. This was because these items may risk exposing this early age group to inappropriate bulimic and anorexic behaviours. Internal reliability $(\alpha=0.73)$ and test-retest reliability $(r=0.56)$ were satisfactory.

\section{Diagnostic Interview for Children and Adolescents}

The Spanish computerized adaptations of the Diagnostic Interview for Children and Adolescents-Revised (DICA-R) $[8,21]$ and the DICA-IV [22] were administered to diagnose ED. The DICA is a semi-structured protocol for children and adolescents that follows the DSM-IV diagnostic criteria [1]. Although the DICA covers several diagnostic areas, in this study we only administered the ED diagnostic area which includes $\mathrm{AN}$ and $\mathrm{BN}$. We obtained the information from the children (DICA-C) at $\mathrm{T} 1$ and from the adolescents (DICA-A) in the follow-up study.

\section{Body Areas Satisfaction Test}

In this study, we used an adapted Spanish experimental translation of the body areas satisfaction test (BAST) [5]. The scale has 8 items which hierarchically measure dissatisfaction with different parts of the body on a scale from 1 (very unsatisfied) to 5 (very satisfied). Internal consistency ( $\alpha=0.83$ ) was good.

\section{Eating Disorder Inventory}

The EDI-2 [10,11] is a 91-item, standardized selfreport consisting of 11 subscales for assessing the following specific cognitive and behavioural dimensions of ED: drive for thinness (DT), bulimia, body dissatisfaction (BD), ineffectiveness, perfectionism, interpersonal distrust, interoceptive awareness, maturity fears, ascetism, impulse regulation, and social insecurity. The mean internal consistency of the several subscales of the EDI-2 in non-clinical population was around 0.80 .

\section{Anthropometric data}

The height and weight of all students who participated in the study (at T1 and at T2) were measured so that their BMI could be calculated. Pubertal stages were collected using pictures of Tanner stages and were self-informed.

\section{Procedure and definition of caseness}

We were given permission by the Catalan Government and head teachers to access the schools. The parents of the children who took part in the study also gave their informed consent in both stages. The study was approved by the Rovina i Vingili University Human Studies Ethic Committee.

The study was designed in two stages over a period of time and the initial stage had two phases. In the first phase, the participants from the initial sample answered the adapted ChEAT and the BAST, and then filled in a questionnaire about sociodemographic data and their parents' professional status. In the second phase, or T1, we took a sample of the participants who scored equal to or above the ChEAT cutoff score (17) and a control group of participants who scored below the cutoff. The ratio of risk subjects to controls in this phase was 3:2. To obtain diagnosis, an individual assessment was made using the ED section of the DICA-C. Parents participated in the study by answering the EDI-2 and confirming their socio-economic data.

Parents were invited to participate again 2 years later (T2). They were contacted by telephone to arrange a personal interview. In this interview, both parents and children were present. They were informed about the follow-up study and the parents signed an informed consent form. Subjects who agreed to participate again were assessed using the BAST, the EDI-2 and other psychological tests (not used in this paper) and their weight and height were individually measured and they were given the ED section of the DICA-A. After assessment the parents of disturbed children were informed.

We created the caseness definition of ED Not Otherwise Specified (EDNOS) by using DSM-IV criteria with the information collected from the DICA$\mathrm{C}$, and DICA-A. Likewise, we used the term subclinical anorexia to describe subjects who fulfil the 
psychopathological criteria of ED based on the fear of gaining weight (B criteria for AN of DSM-IV-TR) or who have self-esteem that is completely based on body weight and shape (C criteria) but who do not satisfy clinical criteria such as amenorrhoea (D criteria) and severity of weight loss (A criteria). We used the term subclinical bulimia to describe subjects who, on the one hand, fulfil the psychopathological criteria of engaging in recurrent episodes of binge eating (A.1 criteria for BN of DSM-IV-TR), recurrent compensatory behaviour (B criteria) and self-evaluation that is completely based on body weight and shape (D criteria) but who, on the other hand, do not satisfy the frequency of binge eating ( $C$ criteria for $\mathrm{BN}$ ) and loss of control during these episodes (A.2 criteria for BN) for clinical bulimia. The subclinical anorexia and subclinical bulimia syndromes and EDNOS were classified as total ED (or any total disorders) in the statistical analyses. T2 also included three cases of $\mathrm{BN}$ in the group of total ED. Table 2 shows the number of total ED.

\section{Data analyses}

We evaluated all analyses separately for mothers and fathers and explored gender differences. However, most of the analyses were presented in the total sample because there were few males.

The $T$ test was used to compare mean scores. When normality of distribution was rejected, we conducted a non-parametric test. Pearson correlation was used to relate continuos variable. To estimate the effect of parents' eating attitudes on ED we performed logistic regression analysis and included individual and social variables that could affect the outcomes as covariates. A level of significance of $P<0.05$ was applied to all hypothesis tests that were two-tailed. The data were analysed with the SPSS statistical software for Windows (version 14.0).

\section{Results}

\section{Relationship between parent's EDI and eating disorders in adolescents}

At T1, the mean ChEAT scores and mean scores of the mother's EDI showed no significant differences between risk/no risk in either gender. Neither were any significant differences found in the mean scores of the father's EDI.

Table 3 shows the mean scores of the mother's EDI in T1 and T2. No significant differences were found between total ED and mother's EDI dimensions in T1. However, when the comparison was made between
Table 3 Mother's EDI mean scores according to the presence of eating disorders in the two stages of the study

\begin{tabular}{|c|c|c|c|c|}
\hline \multirow[t]{2}{*}{ Mother's EDI subscales } & \multicolumn{2}{|l|}{$\mathrm{T} 1$} & \multicolumn{2}{|l|}{$\mathrm{T} 2$} \\
\hline & $\begin{array}{l}\text { Total ED } \\
(n=27)\end{array}$ & $\begin{array}{l}\text { Not ED } \\
(n=147)\end{array}$ & $\begin{array}{l}\text { Total ED } \\
(n=33)\end{array}$ & $\begin{array}{l}\text { Not ED } \\
(n=112)\end{array}$ \\
\hline Body dissatisfaction & $7.29(6.6)^{\mathrm{a}}$ & $6.18(5.8)$ & $8.75(7.7)$ & $5.77(5.4)^{*}$ \\
\hline Drive for thinness & $3.18(4.1)$ & $3.36(3.9)$ & $4.97(5.2)$ & $2.87(3.3)^{*}$ \\
\hline Bulimia & $0.44(0.9)$ & $0.44(1.2)$ & $0.87(1.6)$ & $0.35(1.7)$ \\
\hline Perfectionism & $3.00(4.3)$ & $2.12(2.3)$ & $2.93(4.1)$ & $2.10(2.1)$ \\
\hline Maturity fears & $5.55(3.2)$ & $5.19(3.4)$ & $6.24(4.0)$ & $4.95(3.4)$ \\
\hline Interpersonal distrust & $2.48(2.5)$ & $2.30(3.0)$ & $2.12(2.4)$ & $2.26(3.0)$ \\
\hline Ineffectiveness & $2.96(2.7)$ & $2.04(2.7)$ & $3.03(3.3)$ & $1.71(2.3)^{*}$ \\
\hline Interoceptive awareness & $2.29(2.7)$ & $1.37(2.5)$ & $2.51(3.4)$ & $1.18(2.4)^{*}$ \\
\hline Ascetism & $3.51(2.3)$ & $3.86(2.5)$ & $3.66(2.5)$ & $4.00(2.5)$ \\
\hline Impulsivity & $2.14(3.0)$ & $1.68(2.2)$ & $2.03(3.3)$ & $1.66(2.1)$ \\
\hline Social insecurity & $5.37(2.3)$ & $5.35(2.3)$ & $4.75(1.7)$ & $5.43(2.3)$ \\
\hline
\end{tabular}

* $P<0.05$

${ }^{\mathrm{a}}$ Mean score (standard deviation)

EDNOS (with no subclinical syndromes) and nonEDNOS, the interoceptive awareness was significantly higher $(P<0.05)$ in the first group. This difference was found in females $(M=3.38 ; \mathrm{SD}=3.0$ vs. $M=1.47 ; \mathrm{SD}=2.8$ ) but not in males. In $\mathrm{T} 2$, all adolescents in the group who had been assigned a diagnosis had mothers with significantly higher scores in $\mathrm{BD}, \mathrm{DT}$, ineffectiveness and interoceptive awareness. However, when we analysed these differences by sex, they did not reach statistical significance; only BD was significantly higher in the mothers of males with a diagnosis $(n=4)$. The females who had been diagnosed $(n=29)$ had mothers whose scores were significantly higher in interoceptive awareness and lower in social insecurity.

At $\mathrm{T} 1$ no differences were found in the mean scores of the father's EDI for the presence or absence of ED (Table 4). However, we must take into account the

Table 4 Father's EDI mean scores according to the presence of eating disorders in the two stages of the study

\begin{tabular}{|c|c|c|c|c|}
\hline \multirow[t]{2}{*}{ Father's EDI subscales } & \multicolumn{2}{|l|}{$\mathrm{T} 1$} & \multicolumn{2}{|l|}{$\mathrm{T} 2$} \\
\hline & $\begin{array}{l}\text { Total ED } \\
(n=7)\end{array}$ & $\begin{array}{l}\text { Not ED } \\
(n=57)\end{array}$ & $\begin{array}{l}\text { Total ED } \\
(n=12)\end{array}$ & $\begin{array}{l}\text { Not ED } \\
(n=43)\end{array}$ \\
\hline Body dissatisfaction & $4.71(3.2)^{\mathrm{a}}$ & $4.74(4.5)$ & $4.42(4.1)$ & $5.02(4.6)$ \\
\hline Drive for thinness & $3.43(3.8)$ & $2.26(2.2)$ & $3.92(3.7)$ & $2.21(2.03)^{*}$ \\
\hline Bulimia & $0.00(0.0)$ & $0.19(0.8)$ & $0.00(0.0)$ & $0.21(0.9)$ \\
\hline Perfectionism & $4.71(2.3)$ & $3.28(2.5)$ & $5.50(3.0)$ & $2.86(2.2)^{* * *}$ \\
\hline Maturity fears & $5.57(3.5)$ & $5.72(2.9)$ & $5.17(2.2)$ & $5.81(3.3)$ \\
\hline Interpersonal distrust & $1.14(0.9)$ & $3.54(4.0)$ & $2.17(1.5)$ & $3.93(4.5)^{*}$ \\
\hline Ineffectiveness & $1.14(1.7)$ & $2.12(3.7)$ & $0.75(1.4)$ & $2.58(2.3)^{*}$ \\
\hline Interoceptive awareness & $0.86(1.2)$ & $1.09(2.3)$ & $1.08(2.5)$ & $1.19(2.3)$ \\
\hline Ascetism & $2.29(2.2)$ & $2.51(1.7)$ & $1.75(1.6)$ & $2.65(1.5)$ \\
\hline Impulsivity & $1.29(2.2)$ & $0.68(1.2)$ & $1.25(1.2)$ & $0.77(1.5)$ \\
\hline Social insecurity & $4.43(1.2)$ & $6.05(3.0)$ & $5.08(2.1)$ & $6.28(3.2)$ \\
\hline
\end{tabular}

* $P<0.05$, ** $P<0.01$

${ }^{\mathrm{a}}$ Mean score (standard deviation) 
low power of the test because of the size of the sample ( $n$ of EDNOS $=4$ and $n$ of total ED $=7$ ). In T2, the DT and Perfectionism scores were significantly higher in the group with total ED than in the group without diagnoses. Ineffectiveness and interpersonal distrust were significantly lower.

Correlations were made between both the mother and father EDI-2 subscales scores (T1) and adolescents' EDI-2 subscales scores (T2). A significant relation was found between the BD of the mother and that of her daughter $(r=0.25, P<0.05)$, and between the ascetism of the father and that of his daughter $(r=0.41$, $P<0.05)$. In boys, a significant relation was found with the mother's Bulimia scores $(r=0.26, P<0.05)$.

\section{Predictive capacity of parental EDI on eating disorders in adolescents}

Logistic regressions were made to explore the predictive capacity of parent's EDI dimensions for T1 and T2 on total ED. We introduced the subscales of the mother's EDI or the father's EDI as independent variables, always adjusting for sex, BMI, pubertal stage and BAST scores, and the mother's or father's professional level. At T1, when the mother's EDI subscales were added to the model (Table 5), the diagnoses were significantly explained by perfectionism, and adolescent's BMI and BD. When we used EDNOS as a dependent variable (with no subclinical syndromes), the predictors were the mother's higher interoceptive awareness $(\mathrm{OR}=1.19, P<0.05)$ and the adolescent's BMI and BD. At T2 (Table 5), being male is a factor that protects against ED $(87.0 \%$ less probability than in females). Likewise, the mother's DT and lower social insecurity, and the adolescent's $\mathrm{BD}$ increase the risk of having some form of ED.

It was not possible to make logistic regression analysis with the father's EDI subscales in T1 because the sample was too small. In T2, the total ED were significantly predicted by sex (being male is a mild

Table 5 Regression analyses: mother's variables related to eating disorders (ED) at $\mathrm{T} 1$ and $\mathrm{T} 2$

\begin{tabular}{lll}
\hline & $\begin{array}{l}\text { Any ED in T1 OR } \\
(95 \% \mathrm{Cl})\end{array}$ & $\begin{array}{l}\text { Any ED in T2 OR } \\
(95 \% \mathrm{Cl})\end{array}$ \\
\hline Perfectionsim & $1.19(1.0-1.4)^{*}$ & - \\
BMI & $1.20(1.0-1.4)^{* *}$ & - \\
BAST in T1 & $0.83(0.7-0.9)^{* * *}$ & - \\
Sex & - & $0.13(0.1-0.5)^{* *}$ \\
Drive for thinness & - & $1.20(1.1-1.4)^{* *}$ \\
Social insecurity & - & $0.74(0.6-0.9)^{*}$ \\
BAST in T2 & - & $0.81(0.7-0.9)^{* * *}$ \\
$R^{2}$ & 0.417 & 0.485 \\
\hline
\end{tabular}

$O R$ odds ratio, $C l$ confidence interval

${ }^{*} P<0.05$, * $P<0.01,{ }^{* * *} P<0.001$ protection factor $)(\mathrm{OR}=0.15 ; 95 \% \quad \mathrm{CI}=0.1-0.9$; $P=0.05)$, EDI Perfectionism $\quad(\mathrm{OR}=1.52 ; \quad 95 \%$ $\mathrm{CI}=1.1-2.2 ; \quad P<0.05)$ and $\mathrm{BMI}(\mathrm{OR}=1.38 ; 95 \%$ $\mathrm{CI}=1.1-1.8 ; P<0.05)\left(R^{2}\right.$ of the model $\left.=0.478\right)$.

\section{Discussion}

In this study we cross-sectionally and longitudinally examined the associations between the cognitive and behavioural dimensions of eating pathology in parents and several conditions leading to risk of ED in non-clinical early adolescents. The data support the hypothesis that mothers and fathers influence ED in early adolescents. Two general aspects need to be underlined in our study. Firstly, we observed that parental cognitive and behavioural dimensions have a long-term influence on the development of ED. Secondly, the associations were found in severe forms of ED. So, in T1 we found no differences between the risk of ED assessed with ChEAT and parent's EDI scores. With regard to ED diagnoses, no differences were found when subclinical syndromes and EDNOS were included in T1. However, when we consider only the more severe diagnoses, EDNOS, the interoceptive awareness was higher in the disordered group. This difference was found in females but not in males, and persisted in the long-term (T2). This dimension of the EDI assesses the extent of confusion about or the difficulty in recognizing emotional states and internal sensations related to hunger and satiety, and it has been described as a factor in the development and maintenance of ED [11]. Likewise, at T2 the adolescents with some form of ED also had mothers with higher scores in BD, DT and ineffectiveness. These data coincide with the data found by Woodside et al. [32] in the mothers of anorexic patients, but our study design allows us to show that the mothers had these characteristics before the adolescents developed ED. These relations can be direct or indirect. Mothers can directly influence their children by wishing that they were thinner and withholding food, or by being poor role models, and they can have an indirect influence if general parenting functioning is disturbed [19].

The positive relation between a mother's $\mathrm{BD}$ and an adolescent's BD and some form of ED at T2 may show that $\mathrm{BD}$ is transmitted from mothers to adolescents and that, in combination with other risk factors, it can favour the development of ED. Benninghoven et al. [3] found a positive relation between the BD of patients and mothers in the bulimia nervosa group, but their correlational data did not indicate causality.

In fathers, DT and perfectionism were significantly related to ED. Other authors [32] have found no association between AN and the fathers's eating 
dimensions. Although our sample of fathers is small, the data found underline the possible influence of both parents in the development of ED. Father's perfectionism preceded the development of some ED in their offspring, but we cannot say whether their perfectionism is transmitted as perfectionism to their children and is one of the initiators of the symptoms of ED [29] or whether it is a factor that influences the ED because of disturbed family functioning. Perfectionism in adolescence has been found to be a predictor of ED symptomatology [14], and has been related to the onset of anorexic syndrome in young adulthood [29], and to the course and consequences of restrictive anorexia nervosa [30]. Self-oriented perfectionism has been related to ED characteristics such as BD, DT and diet [12]. Likewise, perfectionism has been found to be a predictor of BN [4].

In $\mathrm{T} 1$ regression analysis, the mother's perfectionism explained EDs when subclinical syndromes were included, but for more severe EDs (EDNOS), the significant variable was interoceptive awareness. Mother's perfectionism was probably a trait of early risk, but other characteristics then affected severity and the long-term. In T2, the mother's DT and social insecurity were risk factors of ED. It is important to point out that at T1 children's BMI was related to ED, but it was not significant at T2, suggesting that high BMI was a factor prior to the onset of ED, as other authors have shown [28]. At T2, we also observed that being female is a risk factor for ED.

Our results suggest that there are some differences between fathers and mothers that are consistent with data from other authors [32]. It seems that a mother who admires thinness and a perfectionist father, have most influence on the risk of ED in adolescents.

Our study has several limitations. The sample of fathers and of males with ED is small, so we could not make a gender analysis or draw conclusions from some data. We did not collect the EDI from all parents, largely because many fathers did not return it.

Despite these limitations, the longitudinal design of the study and the non-clinical population has enabled important findings to be made that should be taken into account in the prevention and family oriented treatment of ED. We conclude that specific cognitive and behavioural dimensions of ED in both parents can influence the development of some forms of ED in early adolescence. Our data support the data provided by other authors $[7,15]$ which indicate that parents may play in role in their children attaching greater importance to their physical appearance and thinness-and, therefore, in the prevalence of ED.

Acknowledgments This research was supported by grants from the Instituto de Salud Carlos III (01/1364 and PI 042596).

\section{References}

1. American Psychiatric Association (1994) Diagnostic and Statistical Manual of Mental Disorders, 4th edn. American Psychiatric Association, Washington

2. Beato-Fernández L, Rodriguez T, Belmonte A, Martínez C (2004) Risk factors for eating disorders in adolescents. A Spanish community-based longitudinal study. Eur Child Adolesc Psychiatry 13:287-294

3. Benninghoven D, Tetsch N, Kunzendorf S, Jantschek G (2007) Body image in patients with eating disorders and their mothers, and the role of family functioning. Compr Psychiatry 48:118123

4. Bulik C, Tozzi F, Anderson Ch, Mazzeo S, Aggen S, Sullivan P (2003) The relation between eating disorders and components of perfectionism. Am J Psychiatry 160:366-368

5. Cash TF (1997) The body image workbook: an 8-step program for learning to like your looks. New Harbingen Publications, Oakland
6. Dancyger I, Fornari V, Scionti L, Wisotsky W, Sunday S (2005) Do daughters with eating disorders agree with their parent's perception of family functioning? Compr Psychiatry 46:135139

7. Davis C, Shuster B, Blackmore E, Fox J (2004) Looking good-family focus on appearance and the risk for eating disorders. Int J Eat Disord 35:136-144

8. Ezpeleta L, de la Osa N, Júdez J, Domènech JM, Navarro JB, Losilla JM (1997) Diagnostic agreement between clinician and the diagnostic interview for children and adolescents-DICA R in a Spanish outpatient sample. J Child Psychol Psychiatry 38:431-440

9. Garcia de Amusquibar AM, De Simone CJ (2003) Some features of mothers of patients with eating disorders. Eat Weight Disord 8:225-230

10. Garner DM (1990) Eating disorder inventory-2 professional manual. Psychological Assessment Resources, Odessa

11. Garner DM (1998) EDI2 Inventario de Trastornos de la Conducta Alimentaria. TEA Ediciones, Madrid
12. Hewitt PL, Flett GL, Ediger E (1995) Perfectionism traits and perfectionistic self-presentation in eating disorders attitudes, characteristics and symptoms. Int J Eat Disord 18:317-326

13. Hill AJ, Franklin JA (1998) Mothers, daughters and dieting: investigating the transmission of weight control. $\mathrm{Br} \mathrm{J}$ Clin Psychol 37:3-13

14. Holston JI, Cashwell CS (2000) Family functioning and eating disorders among college women: a model of prediction. J Coll Couns 3:5-16

15. Laliberte $M$, Boland FJ, Leichner $P$ (1999) Family climates: family factors specific to disturbed eating and bulimia nervosa. J Clin Psychol 55:1021-1040

16. Maloney MJ, Mc Guire JB, Daniels SR (1988) Reliability testing of a children's version of the eating attitudes test. J Am Acad Child Adolesc Psychiatry 27:541-543

17. Miller-Day M, Marks JD (2006) Perceptions of parental communication orientation, perfectionism, and disordered eating behaviors of sons and daughters. Health Commun 19:153-163 
18. Park RJ, Senior R, Stein A (2003) The offspring of mothers with eating disorders. Eur Child Adolesc Psychiatry 12:110-119

19. Patel P, Wheatcroft R, Parker RJ, Stein A (2002) The children of mothers with eating disorders. Clin Child Fam Psychol Rev 5:1-19

20. Pritchard ME (2004) Body satisfaction in adolescent boys and girls: associations with parental behavior. Percept Motor Skills 99:257-258

21. Reich W, Shayka JJ, Taibleson Ch (1991) Diagnostic interview for children and adolescents-revised (DICAR). Washington University, St Louis (unpublished manuscript)

22. Reich W, Leacock N, Shanfeld K (1997) Diagnostic interview for children and adolescents IV (DICA-IV). Washington University, St Louis (unpublished manuscript)

23. Sancho C, Asorey O, Arija A, Canals J (2005) Psychometric characteristics of the children's eating attitudes test in a Spanish sample. Eur Eat Disord Rev 13:338-343
24. Sancho C, Arija A, Asorey O, Canals J (2007) Epidemiology of eating disorders: a two year follow up study in an early adolescent school population. Eur Child Adolesc Psychiatry 16:495-504

25. Smolak L, Levine MP, Schermer F (1999) Parental input and weight concerns among elementary school children. Int J Eat Disord 25:263-271

26. Steiger H, Stotland S (1995) Individual and family factors in adolescents with eating symptoms and syndromes. In: Steinhausen HC (ed) Eating disorders in adolescence. Walter de Gruyter, Berlin, pp 49-68

27. Stern SL, Dixon KN, Jones D, Lake M, Nemzer E, Sansone R (1989) Family environment in anorexia nervosa and bulimia. Int J Eat Disord 8:25-31

28. Swenne I (2001) Changes in body weight and body mass index (BMI) in teenage girls prior to the onset and diagnosis of an eating disorder. Acta Paediatr 90:677-678

29. Tyrka AR, Waldron I, Graber JA, Brooks-Gunn J (2002) Prospective predictors of the onset of anorexic and bulimic syndromes. Int J Eat Disord 32:282-290
30. Wonderlich SA, Lilenfeld LR, Riso LP, Engel S, Mitchell JE (2005) Personality and anorexia nervosa. Int J Eat Disord 37:68-71

31. Woodside DB, Shekter-Wolfson LF (1990) Parenting by patients with anorexia nervosa and bulimia nervosa. Int J Eat Disord 9:303-309

32. Woodside DB, Bulik CM, Halmi KA, Fichter MM, Kaplan A, Berrettini WH et al (2002) Personality, perfectionism, and attitudes toward eating in parents of individuals with eating disorders. Int J Eat Disord 31:290-299

33. Young EA, Mc Fatter R, Clopton JR (2001) Family functioning, peer influence, and media influence as predictors of bulimic behavior. Eat Behav 2:323337

34. Young EA, Clopton JR, Bleckley MK (2004) Perfectionism, low self-esteem, and family factors as predictors of bulimic behavior. Eat Behav 5:273-283 